\title{
EL MARXISMO ARGENTINO Y LA CUESTIÓN DEL CAPITAL MONOPOLISTA
}

\author{
Juan Kornblihtt ${ }^{1}$ \\ Universidad de Buenos Aires, CEICS-CONICET, Argentina \\ http://dx.doi.org/10.5209/rev_NOMA.2013.42343
}

\begin{abstract}
Resumen.- Diferentes corrientes dentro del marxismo argentino coinciden en señalar como una de las causas fundamentales del mal desarrollo económico de la Argentina al hecho de que su inserción internacional se dio en la etapa del dominio del capital monopolista. Por lo tanto, atribuyen las limitaciones históricas del desempeño del capitalismo en la Argentina a una distorsión a la ley del valor por el creciente dominio de relaciones sociales extra económicas. En este artículo, realizaremos una crítica a los principales exponentes de esta posición a partir de retomar la perspectiva de un análisis de la competencia en los términos que Marx los desarrolló en El Capital.
\end{abstract}

Palabras clave.- competencia, capital monopolista, marxismo

\section{Argentinean marxism and the Monopoly Capital problem}

\begin{abstract}
Different schools inside Argentinean Marxism agree to mark as one of the fundamental causes of Argentina bad economic development to the fact that its international market insertion was at the era of the rule of Monopoly Capital. Therefore, they attribute the historical limitations in its development to a distortion of value's law by the increasing rule of extra economic relations. In this paper, we criticize the main exponents of this position from a reappraisal of an analysis of competition based on Marx's Das Kapital terms.
\end{abstract}

Keywords.- competition, monopoly capital, marxism

El debate en torno al capital monopolista marca grandes líneas dentro del marxismo. Encontramos una tradición dominante para la cual el desarrollo del capital se divide en dos grandes etapas. La primera, correspondiente a la estudiada por Marx, estaría caracterizada por la libre competencia. La segunda sería la etapa del imperialismo y del capital monopólico. La principal característica de la etapa monopolista es la regulación de los precios por parte de los monopolios, lo que en cierta medida pondría fin a la competencia en términos económicos. Así, la disputa entre capitales ya no sería por la reducción del precio

\footnotetext{
${ }^{1}$ Investigador argentino del IEALC, Dr. en Historia, docente de la Facultad de Filosofía y Letras de la UBA, integrante del CEICS y becario posdoctoral CONICET. Autor del libro: Crítica del marxismo liberal. Competencia y monopolio en el capitalismo argentino, Ediciones ryr, Buenos Aires, 2008. Mail: jkornblihtt@gmail.com
} 
mediante el desarrollo de las fuerzas productivas, sino una lucha por el control de mercados. Esta posición llega a su máxima teorización a partir de la obra de Baran y Sweezy, en particular con su libro El Capital Monopolista (Baran, 1974). Pero aunque se ha convertido casi en lugar común dentro de la izquierda señalar a los monopolios como los principales responsables de los males del capitalismo, existe una extensa corriente de críticos a la idea de que el capitalismo se encuentra en una etapa regulada por el capital monopolista.

El debate, aunque tiene extensión a nivel internacional, como veremos, poco ha sido puesto de relieve en el estudio de la historia argentina. La idea de la existencia de una etapa dominada por el capital monopolista es aceptada por casi toda la izquierda local quienes lo han dado por cierto, realizando muy poco esfuerzo por comprobarlo. Los numerosos trabajos históricos escritos tanto desde el marxismo como desde otras teorías con intenciones críticas o izquierdistas (dependentismo y en menor medida desarrollismo) señalan la presencia temprana de una dinámica regida por los monopolios extranjeros sin aportar datos empíricos.

\section{La competencia como caótico articulador de la sociedad}

En contraposición con la visión liberal, Marx no consideraba a la competencia como un regulador democrático y eficaz. Sin embargo, coincidía en darle un carácter fundamental en la organización de la sociedad contemporánea. Lo específico del capitalismo en relación a los modos de producción previos es que las relaciones sociales de producción dejan de ser relaciones de sujeción personal directas y pasan a ser relaciones mercantiles indirectas. Cada individuo se comporta como productor independiente de mercancías. Para que esto ocurra, es necesaria la llamada acumulación originaria, por la cual se separa a los productores directos de sus medios de producción. El obrero es a su vez liberado de sus medios de vida y del dominio personal por parte del señor. Esta doble libertad es la que le permite al capital comprarle su única mercancía: la fuerza de trabajo. Mercancía capaz de agregar más valor que el contenido en su propia mercancía. Así se constituyen las clases fundamentales del capitalismo: burguesía y proletariado. $Y$ de esta forma, surge la particular forma de apropiación del excedente por parte de la clase dominante: la plusvalía. La explotación bajo el capitalismo no se da por la fuerza extraeconómica, sino por la acción voluntaria de los individuos que compran y venden mercancías.

El capitalismo aparece así como un "enorme cúmulo de mercancías". Por esa misma razón, la explotación no termina su ciclo en la compra de la fuerza de trabajo, y tampoco en la esfera de la producción. La plusvalía producida por la clase obrera no es apropiada en forma directa por los patrones. Estos están obligados primero a vender sus mercancías. Para hacerlo deben ofrecer una mercancía a menor precio que su rival. Esta dinámica, le permite obtener una proporción de ingreso por sobre el capital invertido mayor que sus rivales. Es decir una ganancia extraordinaria. Pero ese plus no puede ser eterno ya que sus 
competidores, al ver que su rival obtiene una tasa de ganancia mayor que la suya, invertirán sus capitales en esa rama o aumentarán su productividad. El resultado es una progresiva igualación de la tasa de ganancia. Este ciclo volverá a repetirse cuando un capital vuelva a lograr aumentar la productividad y abaratar sus costos y así obtener una ganancia mayor. La plusvalía se constituye así en la masa total de riqueza producida por la sociedad, pero su reparto adopta formas particulares dadas por la competencia. Los más productivos se apropian de una porción mayor, mientras los menos ceden una parte.

La competencia entonces no presupone la existencia de capitales iguales (o infinitesimales como sostiene la teoría de la competencia perfecta), sino una permanente diferenciación entre aquellos que alcanzan una ganancia extraordinaria y capitales que los corren desde atrás. ${ }^{2}$ A la vez, tampoco significa que el precio esté dado o sea externo a los capitales (como también presupone la teoría del equilibrio general y la figura del subastador walrasiano), sino que los capitales más productivos son los que ponen los precios, lo suficientemente altos para obtener una ganancia extraordinaria, y los suficientemente bajos como para desplazar a sus competidores. ${ }^{3}$

Esta dinámica impulsa que en forma permanente aumente su productividad, pero a la vez provoca que aquellos capitales que no logren alcanzar esa ganancia media se fundan. El resultado es una progresiva concentración (aumento de la escala del capital individual) y centralización del capital (cada vez menos capitales en menos manos). Este proceso es el que explica la búsqueda permanente de innovación por parte de los capitalistas. Pero así como explica el desarrollo, permite comprender las contradicciones fundamentales del sistema capitalista. El primer problema que aparece es la imposibilidad de planificar la producción. El mercado es anárquico, lo que implica que sólo se sabe si lo producido podrá ser vendido y en qué cantidad una vez que eso efectivamente ocurra. Esto lleva a un exceso de producción permanente. La siguiente contradicción es aún más profunda. La permanente búsqueda de aumentar la ganancia, como señalamos, obliga aumentar la productividad, es decir la extracción de la llamada "plusvalía relativa". Esto implica una disminución de la proporción de capital variable, es decir fuerza de trabajo por sobre el capital constante (capital fijo, maquinaria, insumos). Este proceso, conocido como "aumento de la composición orgánica del capital", lleva a una reducción de la fuente de plusvalía y, por lo tanto, a una tendencia a la caída de la tasa de ganancia. Esta combinación entre caída de la

\footnotetext{
${ }^{2}$ Los debates sobre la existencia del capital monopolista han intentado de la existencia de diferentes tasas de ganancia concluir que no se cumple lo analizado por Marx, sin embargo la diferenciación de capitales es la forma concreta que adopta la igualación. Para una explicación de proceso, ver, entre otros: "IÑIGO CARRERA, J. 2008. El capital : razón histórica, sujeto revolucionario y conciencia, Buenos Aires, Imago Mundi.

${ }^{3}$ Por supuesto, estamos realizando una apretada síntesis del proceso de transformación de valores en precios de producción y luego en precios de mercado, descrito por Marx en el Tomo III de EI Capital. Explicación que ha dado lugar a un extenso debate. No es nuestro objetivo detenernos en este debate, sino destacar que en la descripción de Marx (aplicable, por los defensores de una etapa monopolista, sólo hasta principios de Siglo $\mathrm{XX}$ ) no existe igualdad entre capitales ni un precio automático en abstracción de éstos.
} 
tasa de ganancia e incapacidad de controlar la producción trae como resultado crisis cíclicas de cada vez mayor envergadura.

En definitiva, para Marx, la dinámica de competencia atraviesa al conjunto de la reproducción del sistema capitalista, y por lo tanto es la clave de su propia superación. Por un lado, el desarrollo de la concentración y centralización de capital impulsa el desarrollo de las fuerzas productivas y además organiza en forma cada vez más socializada la producción (aunque restringiéndolo al interior de cada capital). Por el otro, es la causante de las crisis y por lo tanto de la debilidad de la burguesía en ciertos momentos históricos. Esta doble dinámica es la que le da fuerza estructural a la clase obrera: es a la vez sujeto de una producción cada vez más socializada y tiene la fuerza para aprovechar las contradicciones de la burguesía en la disputa por el poder.

\section{Concentración y centralización: ¿el fin de la competencia?}

Aunque la tendencia general de la acumulación de capital tiende hacia la disminución del número de capitales e incluso Marx esboza la tendencia hacia la centralización absoluta del capital social, el análisis del monopolio como forma de mercado que permita fijar precios en forma permanente por encima del precio de producción es analizado sólo como un caso particular: en la producción de mercancías de origen natural bajo condiciones no reproducibles. Es decir, el problema de la transformación de la ganancia extraordinaria en renta absoluta y diferencial. (Marx, 1998) ${ }^{4} \mathrm{El}$ terrateniente posee efectivamente un monopolio porque se trata de un bien no reproducible. Al existir una diferencia en la calidad de las tierras puestas en producción, aquel terrateniente que tenga una mejor recibirá más por el alquiler. Porque como las condiciones no son reproducibles, los capitales aplicados a la tierra más productiva, aunque su precio de producción individual sea menor, venderán al fijado por el que opera en la peor tierra. Surgirá así una ganancia extraordinaria. Sin embargo, dicha ganancia no quedará en manos de los capitalistas agrarios sino que como consecuencia de la competencia entre ellos pagarán arrendamientos más caros cuanto mejor sea la tierra. Toda ganancia extraordinaria en el agro o la minería (sea resultado de las propiedades de la tierra, sea resultado de la aplicación de tecnología con mayor productividad) irá a parar, entonces, a manos del terrateniente. Así, la ganancia extraordinaria se convertirá en renta.

Aún en el análisis de un caso de monopolio concreto, Marx no plantea el fin de la competencia o una transformación cualitativa en la dinámica capitalismo. Por el contrario, el terrateniente compite en forma permanente con otros terratenientes y esto es lo que le permite obtener una renta no sólo de monopolio sino diferencial en relación a quienes poseen una tierra menos productiva. Es decir, el monopolio aparece como un elemento particular en donde la competencia sigue siendo el mecanismo fundamental de regulación social.

\footnotetext{
${ }^{4}$ Marx también menciona otras posibilidades de monopolio en particular las intervenciones del capital estatal en las ramas donde la alta composición orgánica de capital requiere una magnitud de inversión inicial que no puede realizar un capital individual.
} 
Por el contrario, los neoclásicos piensan los monopolios en forma contrapuesta a la competencia, como una distorsión provocada en forma externa. La economía neoclásica o mainstream tiene como punto de partida el individualismo metodológico. Cada actor es igual y debe recibir una retribución acorde al factor que representa. El mercado, según su concepción, está compuesto por agentes infinitesimales incapaces de influir unos sobre otros. En particular, en la fijación de precios. Estos lejos de ser fijados por cada actor, deben estar "dados": Así el presupuesto para alcanzar el equilibrio es que los competidores deben ser incapaces de determinar los precios a su voluntad. El mecanismo regulador debe ser la oferta y la demanda, y en definitiva lo que fija el precio es lo que cada uno está dispuesto a resignar en pos de un beneficio. En sus propios términos, el equilibrio se alcanza en el punto en el que se igualan las utilidades marginales entre oferentes y demandantes. Ante este funcionamiento perfecto, toda problemática económica es caracterizada como producto de una externalidad que puede estar dada por los monopolios, por fallas de mercado o por la acción estatal. La competencia perfecta es la única capaz de garantizar, según esta teoría, que se alcance el equilibrio general y la distribución democrática del ingreso.

La inexistencia de esta situación en la realidad llevó a la incorporación de la "competencia imperfecta" con presencia de monopolio y los oligopolios que a través de markups provocarían la distorsión en la fijación de precios. El resultado sería el fin de la regulación automática ya que aparece una creciente articulación voluntaria entre los monopolios u oligopolios. Surge entonces toda una línea dentro de la corriente neoclásica que busca analizar las relaciones directas entre los agentes, transformando la competencia en un "juego". El comportamiento de los capitales y la fijación de precios pasan a ser explicados por la "teoría de juegos" y los nuevos equilibrios dependerán de cómo se participe y con qué reglas.

En definitiva, se contrapone una competencia democrática y eficaz contra una regida por monopolios u oligopolios que manipulan los precios. El contraste con el planteo desarrollado por Marx resulta evidente. En ningún momento planteó la existencia de una economía dominada por actores que no se influían ni precios "dados". Sin embargo, la creciente participación del capital bancario y la fusión de empresas cada vez más grande comenzó a transformar la apariencia del mercado. Las tendencias a la concentración y centralización planteadas por Marx se mostraban en toda su dimensión. Incluso en un nivel superior al desarrollado en El Capital. De hecho, la aparición de acuerdos entre capitalistas, fusiones de empresas, más el creciente rol del capital bancario que asociado al industrial aceleraba el crecimiento y la movilidad de los capitales, planteó la necesidad de dar respuesta a este fenómeno.

Desde la política burguesa, y tomando al liberalismo clásico, surgieron medidas para frenar estas distorsione al mercado. Entre las muchas respuestas, aparecieron intentos de lucha antitrust. El hecho más influyente fue la sanción en los EE.UU., en 1890, de la ley Sherman que intentaba limitar la centralización de capital y los acuerdos de precios. Aunque su eficacia para evitar la centralización 
de capital (más allá de casos particulares) es dudable, logró influenciar en términos ideológicos a políticos e intelectuales de todo el mundo. Influencia que como veremos, alcanzó a la Argentina. En 1919, desde la cámara de diputados, el Partido Socialista impulsará una comisión de investigación antitrust en un intento por garantizar el funcionamiento democrático del mercado.

El marxismo analizó la creciente centralización del capital a nivel mundial para comprender las transformaciones políticas a las que se enfrentaba el movimiento revolucionario. Se avanzó en la vinculación entre aparición de monopolios y la creciente internacionalización del capital y la lucha imperialista de los países europeos. Apareció una caracterización del monopolio en Lafargue ${ }^{5}$, Bujarin ${ }^{6}$, Hilferding ${ }^{7}$ y Lenin $^{8}$ aunque la sistematización de una teoría sobre la nueva etapa monopolista llegaría de la mano de dos economistas estadounidenses. Baran y Sweezy (ByS) primero en Teoría del desarrollo capitalista y luego en el Capital monopolista. Allí, plantearon que la etapa surgida en las primeras décadas del siglo XX era radicalmente diferente a la etapa descripta por Marx. El fin de la era del librecambio abría una etapa en la cual los monopolios lentamente comenzaban a regular la producción, perdiéndose estímulo al desarrollo de las fuerzas productivas. A diferencia de la concepción liberal, no se trataba para ellos de un agente externo, sino del fruto de las leyes descriptas por Marx. Pero planteaban que la magnitud de la concentración y centralización ya no implicaba cambios cuantitativos, sino que se trataba de un salto cualitativo. Los capitales podían ahora regular la oferta y la demanda y manejar los precios en forma permanente por encima del valor. Bajar lo precios dejaba de ser rentable, pudiéndose adoptar una estrategia para ganar mercados por el lado de la publicidad o la relación directa con el Estado. Incluso la plusvalía dejaría, para ByS, de ocupar el lugar

\footnotetext{
${ }^{5}$ Lafargue fue uno de los primeros en plantear que la concentración y centralización del capital llevaba al dominio del mercado por parte de trusts. Aunque no fue retomado luego por la tradición marxista, es un antecedente interesante ya que fue quien sacó la conclusiones de su planteo, y sostuvo que el capital había dejado de funcionar como tal y que se estaba paso hacia una "feudalidad capitalista" donde el dominio extraeconómico remplazaba las relaciones sociales basadas en los productores privados e independientes de mercancías. Ver: LAFARGUE, P. 1903. Les trusts américains: leur action--économique--sociale--politique, www.marxists.org.

${ }^{6}$ Bujarin plantea una análisis de la competencia mundial pero como resultado de una articulación entre naciones cuyo mercado interno está dominado por empresas gigantes trustificadas vinculados en forma directa el Estado. La competencia dejaría de ser la forma en la cual cada capital participa en la apropiación de la plusvalía por él producida a ser una disputa política directa entre Estados representantes de los capitales de sus países, con la guerra como forma por excelencia. Ver: BUJARIN, N. 1981. La economía mundial y el imperialismo, Córdoba, Ediciones Pasado y Presente.

${ }^{7}$ Hilferding centra su análisis en la limitación a la movilidad del capital por la mayor composición orgánica de capital que según su planteo llevará a la anulación de la igualación de la tasa de ganancia. El resultado es que los precios aparecen fijados por los monopolios con el único límite de la demanda. Ver HILFERDING, R. 1963. El capital financiero [1910], Madrid, Tecnos.

${ }^{8}$ Lenin retoma retoma los planteos de Bujarin y Hilferding. El capital monopolista es la base de su planteo acerca del imperialismo como fase superior del capitalismo, en tanto y en cuanto la competencia mundial pasa a estar dominada por la política y el dominio del capital monopolista lleva a la manipulación financiera en lugar de al aumento de la plusvalía relativa y al desarrollo de las fuerzas productivas como forma de obtener ganancias. LENIN, V. 1917. El Imperialismo, fase superior del capitalismo, www.marxists.org, Ediciones varias.
} 
central en la generación de riqueza, proponiendo el uso del concepto de "excedente". Aunque no todos los que sostienen la predominancia del capital monopolista como la característica de la nueva etapa coinciden en todos los aspectos con el planteo de ByS, sí acuerdan en señalar éstas como las premisas clave de la nueva competencia fruto de la concentración y centralización de capital. El cambio fundamental, con el cual coinciden en mayor o menor medida los defensores de la "etapa monopolista" es la creciente regulación directa de las relaciones sociales mediante la fuerza. La explotación dejaría de ser extraeconómica y pasaría a manos de una relación directa entre Estado y monopolios, mediante la conformación de monopolios de Estado. La esencia misma del capitalismo, su especificidad en relación a otros modos de producción, estaría en cuestión.

\section{Grandes y chicos en la historiografía argentina}

La cuestión a resolver no es la existencia de un caso u otro de monopolio en cierto período, sino si lo que caracteriza a la acumulación de capital es la preeminencia del capital monopolista. Uno de los pocos debates que encontramos es entre Jorge (1971) y Dorfman (1970) y se restringe al período previo al peronismo y al primer gobierno de Perón. La posición de Dorfman busca reforzar la idea clásica de una alta centralización de capital en la Argentina. Para él, domina una industria oligopólica que coexiste con pequeños capitales. Su base empírica son los censos. En base a ellos, plantea que el $50 \%$ de la riqueza está producida por las 500 empresas más grandes. Sin embargo, EJ discute esta idea con argumentos sólidos. En primer lugar, cuestiona el criterio para seleccionar las empresas grandes, ya que el límite establecido por Dorfman de $500 \mathrm{~m} \$ \mathrm{n}$ incluye empresas de menos de 100 obreros que no tienen posición oligopólica en su rama. En segundo lugar, mide la ocupación de obreros según el tamaño de las empresas, encontrando que el $73.5 \%$ de los obreros están en las empresas pequeñas y medianas, el $10.4 \%$ en las medianas a grandes, y solo el $16 \%$ en las grandes. Por último, y esto es lo más interesante, analiza rama por rama el grado de centralización de la industria y llega a la conclusión que de 190 subramas existentes en los censos, sólo 15 podrían considerarse oligopólicas. Por oligopólicas, entiende aquellas ramas donde el $50 \%$ de la producción está controlado por menos de 4 empresas y entre ellas incluye a la rama harinera en la cual hemos demostrado que la competencia continúa en su dinámica "normal". Jorge concluye que Dorfman confunde la aparición de grandes empresas con la alta monopolización. ${ }^{9}$

El debate al centrarse sólo en datos censales para medir el grado de monopolización de una rama queda trunco. Sin embargo, está claro que las cifras

\footnotetext{
${ }^{9}$ Los términos del debate presentan ciertas dificultades teóricas y metodológicas. En primer lugar, el concepto de industria queda difuso al no establecerse en términos de los regímenes de producción y por tomar como dato fundamental el tamaño del establecimiento. Pierden así de vista que una ensambladora automotriz con miles de obreros puede tener un régimen de manufactura moderna, mientras un pequeño taller textil ser gran industria. Ver: SARTELLI, E. 2007. ¿Cómo se estudia la historia de la industria? Anuario CEICS, 205.
} 
juegan más a favor de la idea de un capitalismo con muchos capitales que compiten, que en una economía centrada en pocos capitales. Situación similar encontramos en el seno del agro pampeano. El sentido común nos marca la existencia de una oligarquía uniforme que no tiene impulsos para la competencia. Lo cual llevaría a la existencia de un sector agrario rentista causante del atraso argentino. Esta imagen como veremos es la base del análisis de gran parte de la izquierda y del reformismo criollo. Sin embargo, en los estudios concretos sobre la dinámica agraria observamos que al igual que el resto de los capitales, se encuentra en permanente competencia. Aunque con un alto grado de centralización de la propiedad total de la tierra, los estudios en diferentes períodos históricos dan cuenta de una fragmentación de la propiedad agraria entre terratenientes chicos y grandes. Se produce una competencia entre ellos que genera una renta diferencial de la tierra entre los propietarios de tierras mejores a partir de que estos últimos por el monopolio natural fijan el precio. Sin embargo cuando la demanda se contrae, se produce una competencia por el abastecimiento del mercado para no salir de producción. Esto lleva a la necesidad de aumentar la productividad de la tierra y bajar los costos. Esta competencia se da a escala interna, pero sobre todo a nivel internacional. Un estudio de Eduardo Sartelli muestra que pese a lo que indican los prejuicios esta competencia llevó a que el agro pampeano invierta en cosechadoras durante el período 1870-1920. A su vez, el estancamiento posterior no tuvo que ver con un comportamiento rentista de los capitalistas agrarias, sino a que ante la reducción de la demanda mundial, y al aumento del proteccionismo de los países consumidores resultaba más racional reducir la inversión (Sartelli, 1994). El conflicto del campo ha reavivado estos debates sobre la cuestión agraria. Una vez más apareció la idea de una oligarquía reaccionaria con un poder monopólico y la existencia de pequeños capitales progresivos. La diferencia es que ahora a la oligarquía se le sumó la acusación de monopolios financieros a los pool de siembra. Lo destacable sobre la aceptación de esta mirada es que los dos bandos en disputa (e incluso partidos de izquierda que no se alinearon ni de uno ni de otro lado) compartieron esta caracterización. Y todos consideraban necesaria la defensa del pequeño capital, que aparecía como un representante del bien común. Esto es resultado de plantear una dicotomía absoluta entre monopolio y pequeños capitales cuando como ya había mostrado Sartelli para el agro de principios de siglo, no son más que las dos caras de la misma moneda. Son dos fracciones del capital que compiten por apropiarse de ganancia, que por la propia dinámica de competencia (y no por una acción extraeconómica) se desplazan unos a otros. Los chicos en el agro no son más que el residuo improductivo, mientras que los más concentrados representan el avance de las fuerzas productivas. ${ }^{10}$ Ninguno representa un carácter favorable a la clase

\footnotetext{
${ }^{10} \mathrm{El}$ agro es unas de las ramas donde el proceso de concentración y centralización tarda más en realizarse, y donde la presencia de pequeños capitales es más masiva. Mientras en las ramas siderúrgicas o automotrices en la Argentina sólo contamos con $5 \circ 6$ empresas, el agro está dominado por cientos de miles. Esto da caldo de cultivo a que las ideas monopolistas tengan mayor desarrollo incluso que en la industria, por el marcado contraste entre grandes y chicos. Sin embargo, no hay diferencias sustanciales con la industria extra agraria. La pervivencia de los pequeños se explica por la menor productividad del agro y las trabas naturales que dificultan la concentración de capital en pocas manos. Sin embargo, el desarrollo de las fuerzas productivas va
} 
obrera. Pero de la mano de la teoría del capital monopolista esto queda desdibujado, apareciendo el pequeño capital como un aliado frente al capital monopolista u oligarquía. ${ }^{11}$

El resto de la historiografìa económica no ha superado este debate. Schvarzer , siguiendo a Jorge Sabato, es uno de los autores que más remarcó el supuesto carácter especulativo de la gran burguesía nacional atribuyendo al carácter oligárquico y monopólico esta característica:

La producción industrial estaba dominada por la gran empresa, la concentración de la propiedad (repartida entre argentinos y extranjeros), y el monopolio de los mercados que abastecía. Ese monopolio, que ya se sentía a comienzos del siglo, sería una de las causas de su menor desarrollo relativo. Algunos de sus mercados estaban controlados por intereses externos (sobre todo, por los manufactureros británicos) y otros estaban repartidos entre los patrones locales. Una Comisión Investigadora de los Trusts, organizada por el Congreso y dirigida por el diputado socialista Juan B. Justo, registró en 1919 la notable generalización de esas pautas de control de la oferta, sin que ello diera paso a ninguna medida legal destinada a restringir esas formas operativas en los mercados locales (Schvarzer, 1998).

Sus pruebas se remiten al trabajo ya analizado de Dorfman y al dictamen de la Comisión Antritrust de la cámara de diputados de 1919. En contraposición, sostiene que los capitales más dinámicos son los pequeños y medianos. Así realiza una apología de capitales como Siam, atribuyendo su decadencia no a la incapacidad de competir a escala internacional, sino a la falta de apoyo estatal. La postura de autores como Schvarzer es que para enfrentar al capital monopolista (especulativo y poco dinámico) el Estado debe actuar dando protección y estimulando la inversión. Su ejemplo a seguir es Corea del Sur. Pero en su apología de la burguesía y el Estado coreanos, se ocupa en forma sistemática de remarcar todos los aspectos positivos en cuanto a cambio tecnológico ocultando que la base fundamental de la entrada de los países del Este asiático en el mercado mundial fue tener los salarios más bajos del mundo. Situación que se repite ahora con la expansión de China.

Otro autor que parte de la premisa del gran capital oligopólico como causante de los males argentinos es Basualdo (Basualdo, 2001). Según su modelo de interpretación de la economía argentina existen dos proyectos en pugna. Por un lado, un capitalismo basado en el mercado interno sostenido sobre los pequeños capitales nacionales y la clase obrera, y por el otro el impulsado por los capitales más concentrados, a la que llama oligarquía diversificada. En el '76, con la dictadura, se impone el proyecto de este último sector. El resultado es la consolidación de una dinámica basada en la valorización financiera en lugar de la

\footnotetext{
haciendo desaparecer esas trabas como lo muestra la conformación de los pool de siembra y la desaparición de pequeños capitalistas que reflejan los diferentes censos agrarios.

${ }^{11}$ Para una crítica detallada a las diferentes caracterizaciones de la estructura de clases y la competencia en el agro actual y a las posiciones de la izquierda en la crisis agraria de 2008, ver: SARTELLI, E., HARARI, F., KABAT, M., KORNBLIHTT, J., BAUDINO, V., DACHEVSKY, F. \& SANZ CERBINO, G. 2008. Patrones en la ruta. El conflicto agrario y los enfrentamientos en el seno de la burguesía, marzo-julio de 2008, Buenos Aires, Ediciones ryr.
} 
producción y la industria. Para comprobar la existencia de esta dinámica, Basualdo se centra en los rankings de empresas de la revista Mercado. Aquí encontramos una repetición del método Dorfman llevado a la enésima potencia. $A$ partir de los rankings concluye que el grado de centralización de capital permite un control de los precios y la manipulación de los préstamos produciéndose así una ganancia extraordinaria de tipo rentista. Sin un análisis de la dinámica particular de los capitales acusados de monopolistas y especuladores, ni series de precios que comprueben su teoría, Basualdo toma como prueba fundamental de su planteo la desaparición de muchos capitales como resultado de la apertura económica posterior de 1976. A esto suma el hecho de que los triunfadores reciban transferencias estatales, ya sea por la nacionalización de la deuda externa como por la posibilidad de especular con los seguros de cambio a través de la llamada tablita de Martínez de Hoz. Atribuye dicha apertura a una revancha de la oligarquía diversificada, como define a la fracción de la burguesía triunfadora. El resultado, para él, es una "primarización" de la economía y una desindustrialización, dónde los aspectos extraeconómicos (saqueo del Estado, corrupción, especulación financiera) reemplazan a la explotación del trabajo. En este planteo aparece, una vez más, un falso contraste entre el capital monopólico y el pequeño capital. Lejos de tener dos dinámicas diferentes, los dos son resultado de la acumulación de capital. La relación con el Estado no marca una dinámica extraeconómica sino que es parte de la realización de la misma. En los momentos de expansión de la capacidad del Estado de recaudar, que coincide con la expansión de la renta agraria, hay posibilidades de desarrollo de los pequeños capitales, ya sea favorecidos por el tipo de cambio, ya sea favorecidos por los subsidios o por protección arancelaria que les permite vender sus mercancías por encima de su valor y compensar su menor productividad. Cuando esta capacidad estatal decae, que coincide con la contracción de la renta agraria, los pequeños capitales se enfrentan en forma abierta a la competencia. ${ }^{12}$ Los triunfadores no son cualitativamente diferentes que los perdedores, sino que son aquellos que por diversas razones tuvieron la productividad suficiente para sobrevivir a la competencia. Muchos de ellos, aunque más grandes que los perdedores, siguen dependiendo de que se compense su baja concentración con transferencias estatales. Que por la contracción de la renta agraria son realizadas en forma creciente por capital externo que llega bajo la forma de endeuda miento, no implica un cambio sustancial. Así, el capital local sigue incapacitado a impulsar la economía nacional y mucho de estos triunfadores desaparecerán o serán vendidos a capitales extranjeros en las sucesivas décadas. Dicha incapacidad se expresará en las crecientes crisis del capitalismo local, que observamos en 1983, 1989 y 2001.

Basualdo no ve esta continuidad y en cambio establece una diferencia tajante entre capital industrial y capital monopolista. El primero coincidiría con la burguesía nacional y vería su base de sustento en la explotación de fuerza de trabajo, algo que aparece como progresivo para Basualdo. Para poder justificar

\footnotetext{
${ }^{12}$ Para una análisis y cuantificación de los ciclos del capital local y la expansión o contracción de la renta agraria ver: INIGO CARRERA, J. 2007. La formación económica de la sociedad argentina, Buenos Aires, Imago Mundi.
} 
esta división, hace otra operación. A los capitales nacionales que logran sobrevivir a la crisis no los considera parte de la burguesía nacional por el sólo hecho de haber crecido y tener una dinámica más cercana a las finanzas y no depender sólo del capital nacional. ${ }^{13}$ Establece así como límite para ser parte de la burguesía nacional ser chico.

En este planteo se evidencia la misma matriz adoptada por los teóricos del capital monopolista. Dentro de estos, Basualdo se coloca del lado de quienes sostienen que esta tendencia es posible de ser revertida con la intervención del Estado, lo cual lo coloca en forma conciente dentro de la tradición del reformismo. Sin embargo, los puntos en común de muchos de sus planteos de defensa del pequeño capital aparecerán en autores marxistas que se revindican revolucionarios.

\section{El marxismo argentino y el capital monopolista}

Por el lado del marxismo, la situación no mejora. Como veremos se adscribe aunque con algunas premisas diferentes a la idea de la vigencia del capital monopolista. Pero en términos empíricos no encontramos investigaciones sobre la estructura industrial que justifiquen esta postura. La principal prueba que toman es la presencia de inversiones extranjeras ya que es una de las características de la etapa monopolista descripta por Lenin. Encontramos, entonces, que la discusión no corre por el camino de las formas que adopta la competencia real, sino que, por el contrario, está supeditada a los modelos teóricos que toma cada teoría. El modelo de capital monopolista es aceptado por las diferentes corrientes marxistas en la Argentina. Tanto estalinistas (incluida su vertiente maoísta) como los trotskistas parten de la idea de que el capital monopólico transforma la dinámica del capitalismo en la Argentina.

\section{4a. Monopolio aplicado a un país dependiente: Oscar Braun}

Empezaremos, sin embargo, por un autor nexo entre el marxismo y el reformismo de autores como Basualdo. Oscar Braun desarrolló una extensa e importante obra sobre el problema de la dependencia. Por un lado, analizó la dependencia en términos del comercio internacional, sosteniendo que una de las claves es el empeoramiento de los términos de intercambio a escala internacional por el monopolio de los países imperialistas de las ramas con mayor composición orgánica de capital (Braun, 1970). En segundo lugar, analizó la implantación del capital monopolista en la Argentina, construyendo un modelo de funcionamiento

\footnotetext{
${ }^{13}$ Un caso paradigmático de esta operación es el realizado con Arcor. Empresa que atraviesa todo el período de la llamada "ISI" comportándose como Basualdo define a la progresiva burguesía nacional (invirtiendo, vendiendo en el mercado interno, teniendo una política nacional) por el hecho de haber sobrevivido a la crisis de los 70 es considerado como Basualdo como parte de la oligarquía diversificada sin poder probar ningún cambio sustancial en su base de acumulación. Para ver en detalle la evolución histórica del caso Arcor y las determinaciones productivas que le permiten sobrevivir e incluso triunfar en el mercado mundial, ver: BAUDINO, V. 2009. El ingrediente secreto: Arcor y la acumulación de capital en la Argentina, 1950-2002, Ediciones ryr.
} 
particular de la economía local. Braun, aunque no se caracteriza por su riqueza empírica, al menos intenta ver la particularidad de aplicar el concepto de capital monopolista en la Argentina intentando no hacerlo en forma mecánica. Con todo, no logra escapar de actuar con un tipo ideal como punto de partida. Para Braun, la consolidación del capital monopolista en la Argentina se da durante el gobierno de Onganía, en particular bajo la política económica de Krieguer Vasena. Su punto de partida es la definición textual del modelo de capital monopolista elaborado por Baran y Sweezy, al que da por sentado y automáticamente da por comprobado. La característica de su implantación en la Argentina está dada por la dinámica de los ciclos económicos locales. El capitalismo en la Argentina está supeditado a depender de las divisas al estar la economía dominada por monopolios que se desarrollan comprando maquinaria afuera, limitando la producción local a los bienes de consumo. Las divisas llegan ya sea por las exportaciones, en mayor medida, ya sea por la inversión directa de capitales extranjeros. Las exportaciones están limitadas a las mercancías agrarias porque los monopolios de los países imperialistas impiden el desarrollo de otras mercancías. La dinámica que sigue el ciclo económico es la expansión de las exportaciones que lleva a un aumento de las reservas que produce un aumento de las importaciones. Esto lleva a un desequilibrio en la balanza comercial porque al crecer la economía interna, crece el consumo de alimentos lo cual lleva a frenar las exportaciones. Comienza así una fase descendente con devaluación y restricción monetaria. Esto provoca un aumento de los precios agrarios por encima de los industriales y, a su vez, caída del salario real y transferencia de riqueza a favor de los sectores agrarios. La fase decreciente restringe las importaciones con lo cual se equilibra la balanza de pagos y el ciclo vuelve a empezar.

Esta dinámica de inflación y devaluaciones permanente comienza a revertirse según plantea Braun con la llegada del capital monopolista. La inversión directa de estos capitales no logra compensar el problema de falta de divisas ya que estos capitales giran sus ganancias al exterior. Sin embargo, le permite al gobierno de Onganía reprimir la inflación mediante la constricción salarial, a la vez que se aplican retenciones al agro para que los precios no estén regidos por el mercado externo. Así, el capital monopolista sienta las bases de una nueva dinámica en la cual el agro deja de ocupar el lugar central y el país está supeditado a la entrada y salida de capitales.

La clave de la aplicación del modelo de capital monopolista en la Argentina por parte de Braun es la supuesta imposibilidad de que los países dependientes exporten a causa del monopolio del mercado mundial por parte de los países imperialistas. Así, las exportaciones argentinas estarían limitadas a aquello que las metrópolis no producen, y a su vez, serían realizadas con términos de intercambio desfavorables. Esta suposición parte de una evidencia real, las exportaciones locales están centradas en mercancía agrarias. El problema está en la explicación de esta causa. Al no realizar un análisis concreto de por qué exportan o no exportan otras rama pierde de vista que la determinación no está dada en términos políticos, sino que depende de la capacidad de competir en el mercado mundial. Siderca es un capital radicado en la Argentina que exporta e incluso es líder en la producción de tubos sin costura, logrando desplazar a muchos capitales 
de países imperialistas. No se trata de un caso aislado. Tenemos toda una región mundial, el Este asiático, que logra incorporarse al mercado mundial como exportador. La clave es una ventaja en la competencia capitalista: su costos laborales sustancialmente menores, fruto de una brutal represión a la clase obrera.

Al no ver las determinaciones económicas en la imposibilidad de Argentina de exportar, Braun ve la factibilidad de enfrentar al imperialismo en términos políticos. Para hacerlo, su propuesta es el apoyo del Estado a los capitales nacionales para lograr la independencia nacional. De esta forma, le atribuye a los pequeños capitales nacionales (que son los que no aparecen aliados a los imperialistas) una capacidad que no tienen. Su imposibilidad de exportar es por razones económicas y la debilidad del Estado para sostenerlos también es material. Éste no puede actuar en abstracción de los capitales sobre los cuales se financia. Y como bien describe Braun, dicha capacidad está supeditada a la obtención de divisas por exportaciones agrarias y, por lo tanto, es cada vez más limitada. Siendo a su vez limitadas las posibilidades del capitalismo nacional. Algo que al plantearse el problema en términos políticos abstractos escapa a la vista de Braun.

\section{4b. El maoísmo: una variante de defensa del pequeño capital}

Ciafardini, economista ligado al maoísmo argentino, también plantea la centralidad del capital monopolista como explicación a los problemas de desarrollo de la Argentina. La clave de su análisis reside en que este país se incorpora al mercado mundial en la etapa imperialista de dominio del capital monopólico. Como prueba sólo menciona a Lenin y su texto El imperialismo...Esta etapa, señala, está caracterizada por la transformación del comercio internacional: se pasa de un intercambio de mercancías entre capitales independientes a la exportación de capitales. El resultado es que las exportaciones tradicionales cambian de sentido. No se trata ya de intercambio de equivalentes, sino del pago de un tributo a los capitales imperialistas que se disputan el dominio (Ciafardini, 2002). La dinámica que se establece es la inversión de capital cuando las ganancias son altas y el aumento de las exportaciones cuando el país se vuelve menos rentable. Así, la Argentina próspera es deficitaria en su balanza comercial, mientras que en los momentos de crisis se vuelve superavitaria. El mecanismo que explica esto es la acción de los monopolios que fugan sus capitales hacia sus casas matrices en lugar de reinvertirlos y, luego, con ese excedente se financia la compra de granos u otros bienes. Aumentan las exportaciones, lo cual sería una forma de pago a los monopolios: "...carnes, cereales, y otras típicas exportaciones argentinas. Esta es la forma del tributo pagado al imperialismo", afirma Ciafardini.

Esta dominación de la Argentina tiene ciertas particularidades. En primer lugar, se da con el apoyo de los sectores oligárquicos a quienes señala como beneficiarios de un poder monopólico. Del otro lado no existe una única potencia sino una disputa entre imperialismos. Dicha disputa es por el control territorial. En la Argentina, durante gran parte del siglo XX se dio entre EE.UU. y Gran Bretaña. El ejemplo que desarrolla Ciafardini es la producción y el comercio de carnes que implicó una disputa entre monopolios de las dos nacionales. Pero señala que, 
como toda competencia monopólica, terminó en un acuerdo y un reparto de cuotas: Gran Bretaña se quedó con el consumo y EE.UU. con la producción.

La dominación de los monopolios externos e internos no se transforma para Ciafardini con el proceso de industrialización por sustitución de importaciones ni mucho menos con el desarrollismo. La característica de lo que él llama "industrialización inducida" es que está supeditada al sector exterior, único generador de divisas. Incluso el peronismo que avanzó en la expropiación agraria mediante el IAPI y la congelación del arrendamiento se vio imposibilitado de sustituir la dependencia del sector externo y terminó siendo derrocado por la oligarquía. En cuanto al desarrollismo, la posición de Ciafardini sobre le dominio del capital monopólico se mantiene. El cambio de esta etapa es la búsqueda de solucionar el problema de la balanza comercial vía la producción de bienes de capital. Pero al hacerlo de la mano del capital extranjero se profundizaron las características ya que se sostuvo en base a beneficios monopólicos. Según plantea, los capitales venían al país porque a través del proteccionismo se les otorgaba un control monopólico del mercado mientras con transferencias estatales se garantizaba una ganancia mínima. Así coincide en la caracterización de Braun sobre el carácter monopolista del gobierno de Onganía. De estos beneficios también se habrían favorecido grupos monopolista con base local, aunque no especifica cuáles.

Por último, Ciafardini analiza el período posterior de la dictadura del 76. Caracterizándola como de desindustrialización, el objetivo sería terminar con el movimiento pendular que provocaba la industrialización inducida y un regreso al modelo agroexportador. La clave era destruir a los capitales locales. Se apeló a un tipo de cambio alto. Esto se hizo porque una condición para esta estrategia era la salida en condiciones de privilegio de los monopolios que habían ingresado en la fase desarrollista. El tipo de cambio alto generado vía endeudamiento era el método. La otra cara del plan era el abastecimiento interno vía importaciones para generar una reducción de precios y controlar la inflación. El escenario así volvía a moverse a imagen del modelo de principios de siglo. El problema, señala Ciafardini, era que la decadencia de GB implicaba que el triángulo con EE UU no podía completarse. Sin embargo, la URSS ocupó ese lugar convirtiéndose en el principal mercado de mercancías agrarias, a la vez que de la mano del gobierno de Videla invertía en el país dividiéndose el control con los EE.UU.

El planteo de Ciafardini tiene muchos puntos de contacto con el Braun. Encontramos en él la idea de un agro dominado por una oligarquía latifundista que trabó el desarrollo del capitalismo argentino desde su génesis. Traba que tendría su origen en la derrota de Mariano Moreno. Esto habría llevado a la Argentina a ser un país dependiente en lugar de una economía desarrollada. El monopolio en el agro (la oligarquía) sería la causante que la traba al desarrollo de las fracciones progresivas del capital nacional, es decir los chacareros. A esta caracterización general, de defensa del pequeño capital, se le suma su concepción del mercado mundial. Considera al comercio exterior como un mecanismo de tributo que paga la Argentina. Tributo que a su vez es disputado por las potencias imperialistas. Coloca así el comercio de mercancías agrarias como una relación de sujeción 
política en lugar de un intercambio mercantil. Obvia de esta forma que al tratarse del comercio de mercancías agrarias, la Argentina no sólo no cede valor sino que recibe aún más que si estas fueran mercancías industriales, ya que las mercancías agrarias son portadoras de renta diferencial de la tierra al venderse por el precio de producción de las tierras peores que no están en la Argentina. Al plantear el comercio exterior en términos extraeconómicos, ve de la misma forma la posibilidad de superar la dependencia nacional. En su postura está planteada la necesidad de una Segunda independencia de la mano del pequeño capital. Al igual que Basualdo, atribuye a éste una capacidad que no tiene. Un poco más conciente de esto, el maoísmo coloca a la clase obrera como el impulsor de esa alianza. Sin embargo, no deja de realizar una apología de un sector que además de enemigo directo de la clase obrera, está incapacitado por su propia naturaleza a vencer al capital más concentrado.

Ciafrdini, junto a otros autores (Cimilo et al., 1973), tiene la virtud de haber realizado estudios empíricos que intentan demostrar la primacía del capital monopolista en la industria argentina. En su análisis concreto, aparecen matices interesantes al dominio del capital monopolista que aunque no cambian su interpretación permiten abordar ciertas discusiones con mayor profundidad. El texto en cuestión describe la presencia de capitales extranjeros (monopolios) que conviven con sectores librecambistas:

En nuestro país, la existencia de sectores monopólicos no se debe a un desarrollo autónomo, sino que es consecuencia de la presencia del capital monopolista internacional que se insertó en nuestra economía (...) y coexiste junto a sectores donde priman las formas de "libre" concurrencia.(Cimilo et al., 1973)

Luego, se profundiza en la relación entre pequeños y grande capitales, sosteniendo que los monopólicos consolidan una plusvalía extraordinaria permanente a costa de los capitales menos concentrados ya que pueden manipular los precios, y en lugar de que éstos bajen con el aumento de la productividad son trasladados al resto de los capitales:

Es así como los sectores oligopolizados obtienen la plusvalía extraída a sus propios obreros y se apropian, as u vez, de parte de la plusvalía que extrae de sus obreros la burguesía no monopolista.(Cimilo et al., 1973)

Desarrollan un argumento ya señalado por otros autores como Mandel ${ }^{14}$, y lo aplican con detalle para la Argentina. De esta forma, buscan probar que el país tiene una estructura monopólica aún cuando se observa una fuerte presencia del pequeño capital, tal como lo demuestra su propio análisis de las diferentes ramas. Los casos que desarrollan en detalle son la industria automotriz, la petroquímica, la harinera y la de cigarrillos. En cada una muestran como se establece una diferenciación entre capitales más concentrados y capitales que no alcanzan la productividad de los mismos. Lo que en ningún caso pueden mostrar es que la

\footnotetext{
${ }^{14}$ Mandel a diferencia de autores como ByS, ve que existe una igualación de la tasa de ganancia, pero considera que sólo se realiza en el sector monopolista y que se trata de una renta de cartel extraordinaria. Mientras que el capital no monopólico es el que tiene la ganancia normal. MANDEL, E. 1972. Tratado de economía marxista, México, Era.
} 
relación que se establece entre ellos no sea de competencia económica. El hecho de que existan transferencias de plusvalía de los sectores menos productivos hacia los más no es prueba de la acción de un capital monopolista o de una explotación extraeconómica, sino que responde a los mecanismos de formación de una tasa media de ganancia tal fueron descubiertos por Marx. De hecho esa transferencia es la forma mediante la cual se realiza la concentración y centralización. A cada avance de esta dinámica de la competencia la escala de los más grandes crece como así de los más pequeños. Capitales que parecían grandes quedan chicos a los pocos años. Se trata de un ciclo permanente que aparece invertido por parte de los teóricos del capital monopolista, al señalar que el capital dinámico es el que está pereciendo, mientras que los ganadores son los estancados.

Pero incluso dentro de los capitales más concentrados observamos en la Argentina una fuerte competencia. En particular, la rama automotriz es la muestra más acabada de la inversión ideológica realizada por la teoría del capital monopolista. Por un lado encontramos que el fracaso del desarrollo de una industria local no se debió a la falta de una mentalidad capitalista, ni tampoco a trabas externas. El IAME tuvo la posibilidad de comprar tecnología e incluso copiar modelos. Su fracaso se debió a su incapacidad de alcanzar la concentración y la productividad suficiente para competir con las empresas más dinámicas (Harari, 2007). Pero incluso, la entrada de capitales extranjeros no implicó un dominio absoluto por un solo capital, sino que se caracterizó por la multiplicidad de empresas que entraron y salieron según su conveniencia, convirtiéndose la Argentina un caso de estudio para analizar la competencia en esta rama (Jenkins, 1985).

En las otras ramas estudiadas por Ciafardini siempre nos encontramos con más de una empresa y una dinámica de competencia permanente. Las claves por las cuales los capitales monopolistas mantienen su posición están dadas por razones estrictamente económicas. Incluso su relación con el Estado responde a está determinación como lo muestra el acceso al crédito, otras de las variables esgrimidas para tildar de monopólicos a los capitales más concentrados.

\section{4c. El trotskismo: Milciades Peña y Víctor Testa, una defensa vergonzante del pequeño capital}

Aunque con diferencias en las consecuencias, el punto de partida de Milcíades Peña, uno de los historiadores más revindicados por el conjunto del trotskismo, es el mismo. El problema es la inserción en la etapa monopólica del capital. La definición de esta etapa es tomada de Lenin y sostiene que la clave es la búsqueda de frenar la tendencia decreciente de la tasa de ganancia. El mecanismo principal es el control directo de los países coloniales y semicoloniales y el mantenimiento del atraso para así aprovecharse de la baja composición orgánica de capital y aumentar la extracción directa de plusvalía. Este planteo implica abandonar por completo uno de los fundamentos del marxismo: la 
igualación de la tasa de ganancia que explica a su vez el conjunto del desarrollo del capitalismo.

En cuanto al análisis específico de la Argentina, a diferencia del estalinismo clásico, no planteará que la Argentina es semi capitalista con resabios feudales, sino un país neo capitalista. Lo cual podría plantear un avance. Pero al centrarse en la idea de capital monopolista sostiene que la Argentina actúa como un capitalismo deformado, lo cual vuelve, al igual que en el caso de los estalinistas, a dificultar la comprensión de la economía argentina. La deformación vendría dada en que este país se salta la etapa de librecompetencia y la industria nacional nace concentrada y centralizada, lo cual le impide a la burguesía nacional jugar un rol progresivo. En base a cifras censales, quiere mostrar el dominio de capitales en condición de monopolio en el agro (en manos de la oligarquía) y en la industria. Decimos "quiere" porque (como también realizaba Ciafardini) al mismo tiempo que asegura que la industria está más concentrada que el agro, señala la existencia de pequeños capitales como una característica particular de la Argentina (Peña, 1986). En definitiva, lo que muestra es una tendencia a la concentración y centralización de capital, pero al igual que ocurre con Dorfman no es suficiente para probar el control monopólico ni a escala nacional y mucho menos internacional. Esto no le impide a MP sacar conclusiones a partir del supuesto dominio monopólico de los capitales más grandes.

La principal característica del modelo que construye son las altas ganancias conseguidas sin necesidad de invertir. Esto llevaría a un comportamiento especulativo tanto en el agro como en la industria produciéndose así una pseudoindustrialización:

En Argentina la elevada cuota de ganancia en las empresas especulativas y la mentalidad burguesa habituada a obtener grandes ganancias en poco tiempo, se trasladan a la industria. $Y$ esta se convierte en una actividad especulativa más en la que ningún capitalista invierte sin la seguridad de elevados porcentajes de ganancia en un plazo perentorio.(Peña, 1986)

Esta afirmación contiene prejuicios sobre el desarrollo de la industria local. El mayor es en torno a la dinámica agraria: MP plantea que el monopolio es el causante de la poca inversión en el agro. Pierde de vista que, como señala Sartelli, esto no ocurre. Por el contrario, encontramos que el agro del período agro exportador es uno de los que mayor composición orgánica tiene en el Mundo a partir de la introducción de cosechadoras (Sartelli, 1997). En cuanto a las otras ramas productivas, MP señala que esas grandes ganancias se obtienen sólo en los mercados ya monopolizados como lo es el de los bienes de consumo. Otra vez, nos encontramos con una serie de prejuicios y confusiones. En primer lugar, no demuestra la existencia de monopolios en las ramas de consumo. Es cierto que son las ramas con mayor concentración y centralización de capital, sin embargo un estudio histórico de la evolución de esas ramas le hubiese mostrado que esto no implica monopolio absoluto, sino competencia mediante el abaratamiento de las mercancías con el necesario aumento de la productividad. En segundo lugar, mezcla dos problemas diferentes: las altas ganancias en los bienes de consumo con el no desarrollo de la producción de bienes de capital. MP al plantear el 
problema en términos de voluntad de los monopolistas, no avanza en la causas por las cuales los bienes de capital no pueden ser producidos en la economía argentina en forma masiva. Cada caso merece un estudio particular, pero la idea que deja abierta es que esto hubiese sido posible de no existir un dominio extraeconómico. Sin embargo, el problema no parece ser ese, sino la imposibilidad de competir por los costos unitarios de la Argentina. A la entrada tardía en el mercado mundial cuando las empresas productoras de bienes de capital están ya consolidadas, hay que sumarle la ausencia de un mercado de tamaño considerable para que las empresas alcancen una concentración adecuada a la competencia mundial y por último los costos laborales no son lo suficientemente bajos para ser receptor de empresas exportadoras de bienes de capital cuando se produce la salida de muchas de ellas de los países centrales, como ocurre por el ejemplo en el Este asiático.

Por el contrario, MP apela a una explicación ad-hoc. El no desarrollo de la producción local de bienes de capital residiría en que los capitales imperialistas no querrían competidores en ese terreno. Este argumento que va de la mano del control absoluto sobre el mercado que tendría el monopolio entra en contradicción con una misma afirmación realizada por MP quien señala que la inversión en bienes de consumo por parte de capitales estadounidenses provoca la competencia con otros capitales connacionales.

El comportamiento especulativo provocado por la preminencia del monopolio lleva a otra consecuencia en el análisis de MP: la inflación. Problema recurrente en la historia argentina, la explicación que encuentra es el accionar voluntario de los monopolios de subir los precios ante el aumento salarial por las crecientes luchas obreras. En lugar de invertir en tecnología y aumentar la productividad como se realizó en Japón, MP ve que los monopolios locales prefieren subir los precios. Pierde de vista que más allá de la baja salarial que se produce, la inflación produce una perturbación en el conjunto de la economía nacional que no beneficia a los capitales en cuestión. Pero además, si esta generase una oportunidad de ganancia extraordinaria permanente y fuese consecuencia voluntaria de los monopolios: ¿por qué en los países centrales, donde la concentración de capital es aún mayor que en Argentina, no se vive con una hiperinflación permanente?

En el mismo sentido que MP, encontramos la posición de su discípulo Víctor Testa (VT). Aunque gran parte de su extenso libro El capital imperialista es una síntesis de autores ya criticados, es interesante detenerse en algunos pasajes de la obra de VT, ya que en pocas palabras resume la caracterización fundamental de la etapa monopolista como un cambio en las características específicas del capitalismo. A la vez, permite entender cómo éstas surgen de una lectura equivocada de El Capital de Marx.

El reparto de la plusvalía sigue una norma uniforme y determinada para todos los capitalistas en el régimen de libre competencia que resulta además equitativa para todos ellos. El monopolio, en cambio, es la negación de esa regla, ya que imponiéndose sobre el mercado, logra aumentar el precio que le corresponde recibir sobre una mercancía y consigue un beneficio adicional para sí. Este hecho, 
poco importante cuando los monopolios son escasos, se convierte en un factor clave cuando éstos alcanzan la hegemonía económica.(Testa, 1975)

Así elimina, sin pudor alguno, los mecanismos de formación de la tasa media de ganancia en los cuales la búsqueda de ganancia extraordinaria, y por lo tanto el reparto no equitativo de la plusvalía, es uno de los motores fundamentales del propio desarrollo capitalista. La forzada imagen de un capitalismo democrático en contraste con la etapa monopolista no es más que una repetición de ideas liberales sobre una realidad que nunca existió. El siguiente paso en este sentido, es atribuirle al capital monopolista un poder extraeconómico que distorsiona las "democráticas" reglas del mercado. Leamos una vez más:

El predominio de la fuerza como medio de reparto de la plusvalía, se convierte en una categoría esencial. El monopolio reemplaza a la fuerza lógica de las relaciones de distribución del capitalismo competitivo por la lógica de la fuerza que impone como único criterio válido. Al nivel más visible de la economía, esto es al nivel de la política, esta situación impone el predominio de la fuerza y de la violencia en la sociedad.(Testa, 1975)

La violencia estatal aparece como una característica específica de la etapa monopolista. De esta forma, VT no hace más que una apología del capitalismo del siglo XIX al negar que la violencia y la desigualdad entre los capitalistas y atribuyendo todos los males de la sociedad actual no al capitalismo, sino al capitalismo monopolista. Por supuesto habría que preguntarle a los obreros masacrados en la comuna de París si acuerdan con VT o a los pequeños capitales y artesanos arrojados a la ruina luego de las sucesivas crisis del siglo XIX. Alguno pensará que acusar a un autor que se autorevindica revolucionario de apología del capital es un insulto. Una vez más leamos sus palabras para que no queden dudas:

Mientras la competencia llevaba a normas estables de reparto entre los capitalistas, y por lo tanto, a un funcionamiento relativamente armonioso del sistema social en lo que a ello respecta, el monopolio exige una ilimitada política de fuerza y es el causante de la violencia generalizada sobre el planeta.(Testa, $1975)^{15}$

\section{Conclusión y perspectivas}

La teoría del capital monopolista toma como propia la perspectiva del pequeño capital. Este no pueden asumir su desventaja frente a los capitales más concentrados resultado de las propias leyes que le dan vida, y por lo tanto denuncia la violación de la competencia como forma de justificar el apoyo de otras fracciones sociales a través del Estado. La izquierda en Argentina al aceptar en forma acrítica la teoría del capital monopolista en su mayor parte asumió como propia esta posición. Incluso en casos en los cuales en principio se niega un alienamiento explícito con el pequeño capital. Como vimos, en general planteó que los problemas del desarrollo nacional fueron resultado de una distorsión a las

\footnotetext{
${ }^{15}$ Idem. El resaltado es nuestro.
} 
leyes del capital y las trabas a la expansión del capital nacional por la limitación extraeconómica impuesta por el capital monopolista. En pocas ocasiones se avanzó en un estudio empírico, primando la justificación de dicha posición a partir de la apelación a citas de autoridad. En los casos, en los cuales sí hubo investigación empírica, los propios resultados ponen en cuestión las conclusiones alcanzadas.

El marxismo argentino lejos está de haber avanzado en dar cuenta de un cambio real en la especificidad de la acumulación de capital tal como la describió Marx. Las relaciones sociales en Argentina se caracterizan por la producción de mercancías. La mediación del Estado y el dominio de algunas empresas en el mercado lejos está de expresar una negación de la ley del valor, sino que son forma necesaria de su realización. Las posturas escolásticas no dan cuenta de las contradicciones reales a partir de un método que permita una posición materialista y científica que oriente la acción política.

En los últimos años, aparecieron unos pocos autores críticos a estas posiciones. Astarita (2006) hizo propio el planteo de la llamada escuela "ortodoxa" cuyos principales exponentes son Shaikh (2006) y Guerrero (1997). Su perspectiva asume la necesidad de retomar el análisis de la competencia internacional. En ese sentido, ha generado un aporte a introducir bibliografía ni siquiera discutida por los referentes clásicos del marxismo argentino. Sin embargo, sus estudios no avanzan en un análisis concreto del lugar de la competencia y el valor. Tal es así que su análisis pierde de vista la especificidades de la inserción internacional en la Argentina al no ver que la industria argentina por su menor competitividad (producto de una menor productividad y de no contar con costos laborales competitivos en relación al Este asiático) debe recibir alguna compensación para poder sobrevivir en la competencia. En este sentido, resulta un aporte el trabajo de Iñigo Carrera, que al dejar de lado la apariencia de la circulación, y las teorías tanto del capital monopolista como de la competencia y estudiar en concreto la especificidad de la acumulación de capital en la Argentina pudo dar cuenta de esta particularidad del capital industrial en la Argentina. A su vez, pudo analizar el rol que juega en ese sentido la renta de la tierra agraria (diferencial y de simple monopolio) y la venta de la fuerza de trabajo por debajo de su valor (Iñigo Carrera, 2007).

El estudio concreto demuestra así ser mucho más potente para comprender los límites del desarrollo del capital industrial y las relaciones con el mercado mundial. En relación la rama agraria, Sartelli por su parte al estudiar las características de la inserción internacional en relación a las exportaciones trigueras y el poder de negociación en contraste con la ganadera en la década del 30 como elemento explicativo de las posibilidades diferentes de negociación de la Argentina en la Conferencia del Trigo en relación al pacto Roca-Runciman (Sartelli, 1994). Kabat, analizó los límites de la producción de zapatos en la competencia internacional lo que permitió explicar que el fracaso del Plan Pinedo como expresión de una estrategia exportadora no fue su no aplicación por cuestiones políticas, sino la inviabilidad de competir en el mercado mundial(Kabat, 2007). También el análisis concreto de la competencia permite explicar por qué la inviabilidad del proyecto la 
producción de auto peronista al explicar los límites del proyecto IKA-IAME (Harari, 2007). Bil, en sus estudio de la historia de la producción de maquinaria agrícola en la Argentina, pudo dar cuenta de los límites como resultado de la falta de la falta de la escala suficiente para industria auxiliar estandarizada a pesar de contar con un mercado interno relativamente grande (Bil, 2009). Pero además de poder explicar los fracasos, el estudio de la acumulación en términos de competencia, permite dar cuenta de los capitales que alcanzan la competitividad suficiente para con base en la Argentina tener un peso significativo en el mercado mundial. Es decir contradecir el límite absoluto a la expansión del capital radicado en los países llamados dependientes planteado por la teoría del capital monopolista. Baudino, a partir de un estudio del a rama de caramelos, pudo explicar el peso de la mayor productividad en la producción de glucosa, proveniente del maíz en el éxito de la empresa Arcor para aprovechar los subsidios y, a diferencia de la mayor parte del capital local, exportar, consolidándose como unos de los principales empresas de caramelos del mundo (Baudino, 2009). Por nuestra parte, el análisis de la producción de tubos de acero sin costura nos permitió explicar el éxito de la empresa Siderca, que también pudo aprovechar las transferencias estatales para constituirse en uno de las principales empresa en su rama, hoy pieza clave del grupo transnacional Tenaris, a partir del aumento de la productividad vía la introducción de tecnología y la regimentación laboral (Kornblihtt, 2010).

En definitiva, los nuevos estudios que dejan detrás de los modelos típicos ideales de funcionamiento de la competencia lejanos a la metodología de Marx y más cercanos a Weber muestran una realidad diferente a la planteada por los clásicos del marxismo argentino. Los problemas de la acumulación de capital en la Argentina pueden explicarse como resultado de la valorización del capital y la búsqueda a través de la competencia por apropiarse de la plusvalía. No hay que apelar a trabas extraeconómicas o distorsiones inexistentes, sino estudiar al capital en su desarrollo concreto. De esta forma, podrá dejar una perspectiva fragmentada propia del pequeño capital y avanzar hacia recuperar una mirada de conjunto del capital propia de la clase obrera. 


\section{Bibliografía:}

ASTARITA, R. 2006. Valor, mercado mundial y globalización, Buenos Aires, Kaicron.

BARAN, S. 1974. Capital monopolista, Madrid, Siglo XXI.

BASUALDO, E. M. 2001. Concentración y centralización del capital en la Argentina durante la década de los noventa : una aproximación a través de la reestructuración económica y el comportamiento de los grupos económicos y los capitales extranjeros, Bernal (Argentina), Universidad Nacional de Quilmes ediciones2001.

BAUDINO, V. 2009. El ingrediente secreto: Arcor y la acumulación de capital en la Argentina, 1950-2002, Ediciones ryr.

BIL, D. 2009. La industria argentina de maquinaria agrícola (1870-1975): evolución y problemas de su desarrollo. Buenos Aires: Instituto de Investigaciones Gino Germani.

BRAUN, O. 1970. Desarrollo del capital monopolista en Argentina, Editorial Tiempo Contemporáneo.

BUJARIN, N. 1981. La economía mundial y el imperialismo, Córdoba, Ediciones Pasado y Presente.

CIAFARDINI, H. 2002. Contribución a los estudios sobre la economía argentina. In: CIAFARDINI, H. (ed.) Textos sobre economía política e historia. Buenos Aires.

CIMILO, E., LIFSCHITZ, E., GASTIAZORO, E., CIAFARDINI, H. \& TURKIEH, M. 1973. Acumulación y centralización del capital en la industria argentina, Buenos Aires, Editorial Tiempo Contemporáneo.

DORFMAN, A. 1970. Historia de la industria argentina, Buenos Aires, Solar/Hachette.

GUERRERO, D. 1997. Historia del pensamiento económico heterodoxo, Madrid, Trotta.

HARARI, I. 2007. Crónica de una privatización anunciada: alcances y límites de la producción automotriz bajo el peronismo. Anuario CEICS, Ediciones ryr, № 1.

HILFERDING, R. 1963. El capital financiero [1910], Madrid, Tecnos.

IÑIGO CARRERA, J. 2007. La formación económica de la sociedad argentina, Buenos Aires, Imago Mundi.

IÑIGO CARRERA, J. 2008. El capital : razón histórica, sujeto revolucionario y conciencia, Buenos Aires, Imago Mundi.

JENKINS, R. 1985. Internationalization of Capital and the Semi-Idustrialized Countries: The Case of the Motor Industry. Review of Radical Political Economics, 17.

JORGE, E. F. 1971. Industria y concentración económica, Siglo Veintiuno Argentina Editores. 
KABAT, M. 2007. La exportación que no fue. El caso de la producción de calzado argentino en la década del '40. Anuario CEICS, Ediciones ryr, № 1.

KORNBLIHTT, J. 2010. La expansión exportadora de Siderca y la competencia en el mercado mundial de tubos sin costura (1954-2000). Comercio exterior.

LAFARGUE, P. 1903. Les trusts américains: leur action--économique--sociale-politique, www.marxists.org.

LENIN, V. 1917. El Imperialismo, fase superior del capitalismo, www.marxists.org, Ediciones varias.

MANDEL, E. 1972. Tratado de economía marxista, México, Era.

MARX, K. 1998. El capital: crítica de la economía política, México, Siglo veintiuno.

PEÑA, M. 1986. Industrialización y clases sociales en Argentina, Buenos Aires, Hyspamerica.

SARTELLI, E. 1994. Cuando Dios era argentino. La crisis del mercado triguero y la agricultura pampeana (1920-1950). Anuario Universidad Nacional de Rosario.

SARTELLI, E. 1997. Rios de oro y gigantes de acero: Tecnología y clases sociales en la región pampana (1870-1940). Razón y revolución, 2.

SARTELLI, E. 2007. ¿Cómo se estudia la historia de la industria? Anuario CEICS, 205.

SARTELLI, E., HARARI, F., KABAT, M., KORNBLIHTT, J., BAUDINO, V., DACHEVSKY, F. \& SANZ CERBINO, G. 2008. Patrones en la ruta. El conflicto agrario y los enfrentamientos en el seno de la burguesía, marzo-julio de 2008, Buenos Aires, Ediciones ryr.

SCHVARZER, J. 1998. Nuevas perspectivas sobre el desarrollo industrial argentino (1880-1930). Anuario IEHS, 13.

SHAIKH, A. 2006. Valor, acumulación y crisis, Buenos Aires, Ediciones ryr.

TESTA, V. 1975. El capital imperialista, Buenos Aires, Fichas. 